\title{
Correspondence
}



\section{No refraction in Leonardo's orb}

Martin Kemp suggests that Leonardo da Vinci's knowledge of optics and minerals is evident in the representation of the orb in the Salvator Mundi painting (Nature 479, 174-175; 2011).

But I question his interpretation that the double contour of the heel of the hand holding the orb depicts the birefringence (double refraction) arising in a calcite orb.

The painting shows no optical distortion in the folds of the clothes, for example, as would be expected from refraction by an orb of calcite, quartz or glass, or even a water-filled glass vessel. In reality, an inverted and nonlinearly reduced image of most of the chest, arm and shoulder would appear within the orb's outline; the heel of the hand would appear in the top half of this image.

An additional image (nonlinearly enlarged and upright) would open up within the inverted first image if part of the hand or cloth were near the central back surface of the orb. Such refractive effects would be more obvious than any due to birefringence in calcite.

The double contour of the hand continues slightly outside the orb, hence it could be due to a previous stage of the painting, or pentimento. The absence of refraction or reflection effects suggests that the orb depicts an idealized celestial sphere, with the painted specks on its surface representing heavenly bodies. André J. Noest Utrecht University, the Netherlands. a.j.noest@uu.nl

Martin Kemp replies:

As far as we can tell, given the damage to the Salvator Mundi, the garments behind the sphere are indeed undistorted (Nature 479, 174-175; 2011). But it is wrong to assume that Leonardo da Vinci painted all of the optical phenomena he knew about.

No painters at the time depicted such things as the blur of fast-moving objects or the refraction of limbs in water, because that would have been bad pictorial etiquette. The first blurring in a painting is not seen until more than 100 years later, in the work of Diego Velásquez. Leonardo specifically said that such extreme effects are for the speculatori (natural philosophers), not the painters. To show the full effects of the sphere on the drapery behind would have been grotesque in a functioning devotional image.

Contrary to what has become a common belief, Leonardo did not aspire to represent his subjects as if he were a scientist recording natural phenomena. Rather, he was remaking nature synthetically in the functional context of specific paintings (M. Kemp Leonardo revised edition, Oxford University Press; 2011).

The birefringence is a side issue and not important for the attribution. The conservator of the picture cannot tell whether the double heel of Christ's hand is deliberate, a result of damage or a pentimento.

Martin Kemp University of Oxford, UK. martin.kemp@trinity.ox.ac.uk

\section{European vultures' altered behaviour}

Europe's last remaining populations of griffon vultures (Gyps fulvus) in Spain and southern France have taken to killing livestock, according to the many reports received by authorities. This has provoked discontent and incurred vengeance from some farmers. The alarming departure of the vultures from their normal role as carrion scavengers seems to stem from an increased competition for food resources, which may be caused by changes to European sanitary and conservation policies.

There were 1,165 reported cases of griffon vultures killing domestic livestock in 2006-10 in northern Spain alone, with compensation to farmers costing almost $€ 265,000$ (US\$350,000). Unofficial control by poisoning killed 243 griffon vultures in the same period - an ill-conceived action, given that these and other avian scavengers are already severely threatened in Europe.

Changes to European sanitary legislation introduced in 2002 to help combat the spread of bovine spongiform encephalopathy coincided with the introduction of new regulations for animal husbandry, such that any livestock carcasses were collected from farms and destroyed. The combined effects of less carrion and an increase in the griffon-vulture population in Europe may be to blame for the present situation.

Efforts to resolve this conflict are constrained by a lack of solid scientific data, not helped by mounting public alarm and political pressure. Sanitary and other authorities must work with farmers, scientists and conservation groups to produce guidelines to solve the problem in both the short and the long term.

Antoni Margalida Institute of Ecology and Evolution, University of Bern, Switzerland.

antoni.margalida@iee.unibe.ch David Campión Navarre Environmental Management, Pamplona, Navarra, Spain. José A. Donázar CSIC Doñana Biological Station, Seville, Spain.

\section{The cell was defined 150 years ago}

Anthony Hyman and Kai Simons recount how E. B. Wilson described a cell in 1896 as "the basis of the life of all organisms" (Nature 480, 34; 2011). But it was an almost-forgotten German biologist, Max Schultze, who 150 years ago laid an earlier foundation stone for cell biology by defining the cell in terms of what it contained rather than its boundary.

In an 1861 article, 'On muscleparticles and what we should call a cell' (Archiv für Anatomie, Physiologie und wissenschaftliche Medicin 1-27; 1861), Schultze rejects the definition of a cell put forward by Robert Hooke almost two centuries earlier.

On the basis of microscopic observations of sections of cork, Hooke in 1665 had introduced the term cell, after the Latin cella, for 'little room with a rigid wall'. Schultze argued that the existence of an enveloping wall, as found in plants, is not an essential criterion for defining a cell.

Schultze based his conclusion on his comparative studies of protoplasmic material from animal muscle tissue and from protozoans. From his observations of these soft, flexible, living systems, Schultze redefined the cell as a "naked speck of protoplasm with a nucleus" (see A. Reynolds J. Hist. Biol. 41, 307-337; 2008).

It could be argued that this more accurate protoplasmnucleus description of the cell marked the origin of cell biology as a new scientific discipline, encompassing cells as evolving units of all extant and extinct forms of life.

U. Kutschera Institute of Biology, University of Kassel, Germany. kut@uni-kassel.de

\section{CONTRIBUTIONS}

Readers are welcome to comment online: www.nature.com/nature. 